\title{
Nicotine Blocks Kainic Acid-Induced Wet Dog Shakes in Rats
}

\author{
R. Douglas Shytle, Ph.D., Cesario V. Borlongan, Ph.D., and Paul R. Sanberg, Ph.D.
}

Systemic or central administration of kainic acid (KA) in rats results in the expression of wet dog shakes (WDS) followed by motoric seizures and convulsions, which are associated with limbic neurotoxicity. Although a number of neurotransmitter systems are thought to be involved with this KA-induced syndrome, little is known about the possible influence of cholinergic nicotinic receptor modulation. In the study presented here, we pretreated rats with saline or $0.5 \mathrm{mg} / \mathrm{kg}$ nicotine base followed 15 minutes later by $12.0 \mathrm{mg} / \mathrm{kg} \mathrm{KA}$ and then observed the incidence of WDS between 45 and 120 minutes post-KA injection. Rats pretreated with nicotine exhibited significantly less WDS than those pretreated with saline ( $\mathrm{p}<.001$ ). Whereas the mechanism for this nicotine effect is currently not known, future experiments will look at dose-response relationships, the role of nicotine receptors, and possible neuroprotective potential of nicotine in this KA-induced syndrome.

[Neuropsychopharmacology 13:261-264, 1995]
KEY WORDS: Nicotine; Cholinergic; Kainic acid;

Wet dog shakes; Seizures

In adult rats, systemic or intraventricular administration of the glutamate analogue, kainic acid (KA), results in the expression of a syndrome characterized by behavioral automatisms such as wet dog shakes (WDS), motoric seizures, excessive salivation, whole body tremor, aggression, hyperactivity, and brain neurotoxicity (Lenicque et al. 1979). Although many brain areas are affected by KA administration, the hippocampus is most affected (Ben-Ari 1985). The neurodegeneration of cells in the CA3/CA4 regions results in epileptiform activity displayed by CA1 pyramidal cells, which is characterized by an enhanced NMDA-mediated excitatory phase with an apparent loss of GABA-mediated postsynaptic inhibition (Turner and Wheal 1991; Wil-

From the Division of Neurological Surgery (RDS, CVB, PRS), Departments of Surgery, Psychiatry, Neurology, and Pharmacology (PRS), University of South Florida, Tampa, Florida.

Address correspondence to: Paul R. Sanberg, Ph.D, Division of Neurological Surgery, Department of Surgery, 12901 Bruce B. Downs Blvd., MDC Box 16, Tampa, FL 33612-4799.

Received February 13, 1995; revised April 24, 1995; accepted May 3, 1995. liams et al. 1993). Because of both the behavioral and neurologic similarities, this KA-induced syndrome has been proposed as an animal model for human temporal lobe epilepsy (Ben-Ari 1985; Williams et al. 1993).

KA-induced WDS are similar to those observed after morphine withdrawal (Fuller and Olney 1979) and are influenced by drugs that affect a number of neurotransmitter and neuropeptide systems including GABA (Lenicque et al. 1979), excitatory amino acids (Dawson and Wallace 1992), serotonin, norepinephrine, dopamine, endogenous opioids (Velísek et al. 1994; Worms et al. 1981; Fuller and Olney 1979), and substance P (Velázquez et al. 1993).

WDS produced by other drugs have been proposed as an animal model of Tourette's syndrome (Handley and Dursun 1992), a hyperkinetic motor disorder characterized by repeated automatisms such as motor and vocal tics, and we (Sanberg et al. 1988; Silver et al. 1994), as well as others (Reveley et al. 1994), have reported that nicotine may be therapeutically active in reducing tic frequency and severity in these patients. Nicotine is thought to act primarily at acetylcholine nicotinic receptors, where it activates the presynaptic release of acetylcholine, monoamines (Balfour 1982), and 
GABA (Wonnacott et al. 1989). Nicotine has also been found to alter the brain levels of several hormones and neuropeptides (Andersson et al. 1988), including nerve growth factor receptor expression (Terry and Clark 1994). However, little is known about the role of cholinergic systems underlying KA-induced WDS and, to our knowledge, no studies have investigated the effects of nicotinic agonists or antagonists on KA-induced WDS. Therefore, the present experiment was designed to investigate the ability of nicotine to influence the WDS produced by systemic administration of KA.

\section{METHODS}

Sixteen experimentally naive, 8 week old, male Sprague-Dawley derived albino rats $(\sim 250 \mathrm{~g})$, each received subcutaneous injections of first saline or 0.5 $\mathrm{mg} / \mathrm{kg}$ nicotine (free base dissolved in saline) followed 15 minutes later by $12.0 \mathrm{mg} / \mathrm{kg}$ kainic acid (dissolved in saline and buffered to a $\mathrm{pH}$ of 7.2). Based on separate preliminary experiments investigating temporal parameters, rats were observed for rapid axial head and body rotations or "wet dog shakes" (WDS) between 45 and 125 minutes post-KA injection in their home cages. An experimenter, who was blind to the treatment conditions, counted the number of WDS over 5-minute periods at 15-minute intervals. The data were analyzed statistically with the use of an ANOVA with repeated measures followed by post hoc tests (Scheffé) to detect group differences at each time point.

\section{RESULTS}

As shown in Figure 1, the incidence of KA-induced WDS was less prevalent in those rats pretreated with nicotine than in those pretreated with saline. This was confirmed by the ANOVA with repeated measures, which indicated a significant effect of "group" $(F=17.6$; $d f=1,14 ; p<.001)$ and "time" $(F=5.1 ; d f=5,70 ; p<$ .001) with a significant "group" by "time" interaction $(F=4.0 ; d f=5,70 ; p<.005)$. Further post hoc analyses revealed that significant group differences occurred at between 80 and 110 minutes post-KA injection $(p<.01)$.

Although not explicitly quantified by experimenters, nicotine pretreated rats displayed marked hypoactivity characterized by a flaccid appearance and a tendency to lie outstretched on the cage floor. This hypoactive response subsided rapidly 15 to 20 minutes postnicotine injection at which time the rats' behavior appeared normal.

\section{DISCUSSION}

The present findings are in agreement with others who have reported that systemic administration of KA in rats

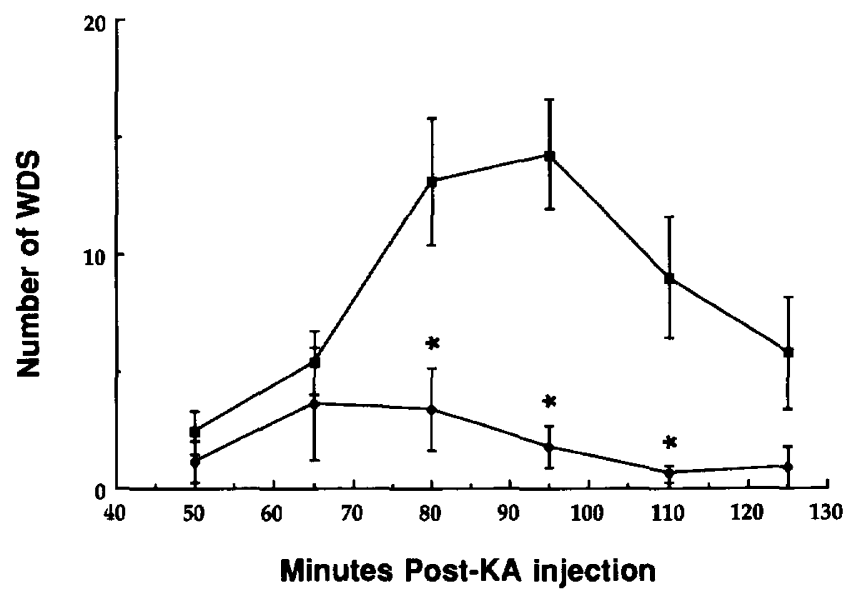

Figure 1. The effects of $0.5 \mathrm{mg} / \mathrm{kg}$ nicotine pretreatment on mean WDS produced by $12.0 \mathrm{mg} / \mathrm{kg}$ kainic acid for data collected over 5-minute periods at 15-minute intervals. Range bars indicate SEM ( $n=8$ /group) and asterisks indicate significant difference at $p<0.01$. Upper line with squares represents saline and lower line with diamonds represents nicotine.

at similar doses used in the present experiment produce WDS that peak in appearance at 90 minutes and subside at around 120 minutes postinjection (Worms et al. 1981). Furthermore, we report for the first time that a high dose of nicotine profoundly attenuates the expression of WDS induced by KA.

In agreement with previous behavioral studies using similar doses of nicotine (Clarke and Kumar 1983), nicotine pretreated rats displayed marked hypoactivity which subsided rapidly 15 to 20 minutes postnicotine injection. It is unlikely that this depressant effect of nicotine masked the behavioral effects of KA, as the reduction in KA-induced WDS occurred between 95 and 125 minutes postnicotine injection, at a time when the benavioral effects of nicotine have largely dissipated or may even be slightly stimulatory (Clarke and Kumar 1983). Whether this ability of nicotine to block the WDS produced by KA is pharmacokinetic or pharmacodynamic remains to be determined; however, WDS are observed after withdrawal from chronic nicotine exposure (Malin et al. 1992) suggesting that central nicotinic mechanisms may be involved with the expression of WDS.

Because GABA agonists strongly inhibit both the behavioral and neurotoxic consequences of KA administration (Lenicque et al. 1979; Worms et al. 1981), it is possible that nicotine blocked KA-induced WDS through a GABA-mediated process. In fact, nicotine has been reported to stimulate the spontaneous release of GABA from hippocampal synaptosomes (Wonnacott et al. 1989). On the other hand, it has been reported that the nicotinic acetycholine receptor shares structural homologies between both $\mathrm{GABA}_{\mathrm{A}}$ (Schofield et al. 
1987) and glycine receptors (Grenningloh et al. 1987), which may permit nicotine to interact with ligand-gated ion channels other than the nicotinic receptor. In this regard, nicotine has been found to both partially inhibit whole-cell N-methyl-D-aspartate (NMDA) induced responses and displace MK-801, a noncompetitive NMDA receptor antagonist, in rat cortical neurons (Aizenman et al. 1991). Therefore, because NMDA receptor activation is thought to contribute significantly to both the behavioral and neurotoxic effects of systemically administered KA (Clifford et al. 1990), it is possible that nicotine may have inhibited KA-induced WDS by interacting directly with the NMDA receptor complex.

In light of the present findings and the growing body of evidence now suggesting that nicotine may have neuroprotective properties against the neurotoxic consequences of excitatory amino acid exposure (Akaike et al. 1994; Marin et al. 1994), as well as the neurodegeneration produced by surgical brain transection (Janson and Moller 1993), more extensive experiments are warranted to investigate the dose parameters, the roles of peripheral and central nicotinic receptors, and possible neuroprotective potential of nicotine in this KA-induced behavioral and neurodegenerative syndrome.

\section{ACKNOWLEDGMENTS}

This work was supported, in part, by grants from the Smokeless Tobacco Research Council and The National Institute of Neurological Disease and Stroke (RO1 NS. 32067-01A1). We would also like to thank Shajmil Ross for her assistance as a blind rater.

\section{REFERENCES}

Aizenman E, Tang LH, Reynolds IJ (1991): Effects of nicotinic agonists on the NMDA receptor. Brain Res 551:355-357

Akaike A, Tamura Y, Yokota T, Shimohama S, Kimura J (1994): Nicotine-induced protection of cultured cortical neurons against $\mathrm{N}$-methyl-D-aspartate receptor-mediated glutamate cytotoxicity. Brain Res 644:181-187

Andersson K, Fuxe K, Eneroth P, Harfstrand A, Agnati L (1988): Involvement of $D_{1}$ receptor dopamine receptors in the nicotine-induced neuroendocrine effects and depletion of diencephalic catecholamine stores in the male rat. Neuroendocrinology 48:188-200

Balfour DJK (1982): The effects of nicotine on brain neurotransmitter systems. Pharmacol Ther 16:269-282

Ben-Ari Y (1985): Limbic seizure and brain damage produced by kainic acid: Mechanisms and relevance to human temporal lobe epilepsy. Neuroscience 14(2):375-403

Clarke PBS, Kumar R (1983): The effects of nicotine on locomotor activity in nontolerant and tolerant rats. Br J Pharmacol 78:329-337

Clifford DB, Olney JW, Benz AM, Fuller TA, Zorumski CF (1990): Ketamine, phencyclidine, and MK-801 protect against kainic acid-induced seizure-related brain damage. Epilepsia 31:382-390
Dawson R, Wallace DR (1992): Kainic acid-induced seizures in aged rats: Neurochemical correlates. Brain Res Bull 29:459-468

Fuller TA, Olney JW (1979): Effects of morphine and naloxone on kainic acid neurotoxicity. Life Sci 24:1793-1798

Grenningloh G, Rienitz A, Schmitt B, Methfessel C, Zensen M, Beyreuther K, Gundelfing ED, Betz (1987): The strychine binding subunit of the glycine receptor shows homology with nicotinic acetycholine receptors. Nature 328 : 215-220.

Handley SL, Dursun SM (1992): Serotonin and Tourette's syndrome: Movements such as head shakes and wet dogshakes may model human tics. In Advances in the Biosciences, vol 85. Oxford, Pergamon, pp 235-253

Janson AM, Moller A (1993): Chronic nicotine treatment counteracts nigral cell loss induced by partial mesodiencephalic hemitransection: An analysis of the total number and mean volume of neurons and glia in substantia nigra of the male rat. Neuroscience 57:931-941

Lenicque PM, Wepierre J, Cohen Y (1979): Protection by 4-aminohex-5-enoic acid ( $\gamma$-vinyl GABA) and hypobaric hypoxia against kainic acid neurotoxicity. Psychopharmacology 66:51-53

Malin DH, Lake JR, Newlin-Maultsby P, Roberts LK, Lanier JG, Carter VA, Cunningham JS, Wilson OB (1992): Rodent model of nicotine abstinence syndrome. Pharmacol Biochem Behav 43:779-784

Marin P, Maus M, Desagher S, Glowinski J, Prémont J (1994): Nicotine: A new protective agent? Neuroreport 5:1851

Reveley MA, Bird R, Stirton RF, Dusun SM (1994): Microstructural analysis of the symptoms of Tourette's syndrome and the effects of a trial use of transdermal nicotine patch. J Psychopharmacol Suppl A30:117

Sanberg PR, Fogelson HM, Manderscheid PZ, Parker KW, Norman AB, McConville BJ (1988): Nicotine gum and haloperidol in Tourette's syndrome. Lancet 1:592

Schofield PR, Darlison MG, Fujita N, Burt DR, Stephenson FA, Rodriquez H, Rhee LM, Ramachandran J, Reale V, Glencorse TA, Seeburg PH, Barnard EA (1987): Sequence and functional expression of the $\mathrm{GABA}_{\mathrm{A}}$ receptor shows a ligand-gated receptor super-family. Nature 328:221-227

Silver AA, Shytle RD, Philipp MK, Sanberg PR (1995): Transdermal Nicotine in Tourette's Syndrome. In Clarke PBS, Quik M, Thurau K (eds), The Effects of Nicotine on Biological Systems, Advances in Pharmacological Sciences. Boston, Birkhaüser Verlag, pp 293-299

Terry AV, Clarke MS (1994): Nicotine stimulation of nerve growth factor receptor expression. Life Sci 55:91-98

Turner DA, Wheal HV (1991): Excitatory synaptic potentials in kainic acid-denervated rat CA1 pyramidal neurons. J Neurosci 11(9):2786-2794

Velázquez RA, Xiaofeng S, Kurtz HJ, Larson AA (1993): Possible role of the n-terminus of substance $P$ in kainic acidinduced toxicity in rats. Brain Res 624:109-114

Velísek L, Bohacenkova L, Capkova M, Mares P (1994): Clonidine, but not ritanserin, suppresses kainic acid-induced automatisms in developing rats. Physiol Behav 55(5): 879-884

Williams S, Vachon P, Lacaille JC (1993): Monosynaptic GABA-mediated inhibitory postsynaptic potentials in CA1 pyramidal cells of hyperexcitable hippocampal slices from kainic acid-treated rats. Neuroscience 52(3):541-554 
Wonnacott S, Irons J, Rapier C, Thorne B, Lunt GG (1989): Worms P, Willigens M, Lloyd KG (1981): The behavioral Presynaptic modulation of transmitter release by nicotinic receptors. Prog Brain Res 79:157-163 effects of systemically administered kainic acid: A Pharmacologic analysis. Life Sci 29:2215-2225 